\title{
Exploration on the Construction of College Students' Party Building Platform under New Media Environment
}

Haitao Li

College of Information and Control Engineering, Jilin Institute of Chemical Technology, Jilin City, Jilin Province,

466137114@qq.com

Keywords: New media; Party building; Effectiveness

Abstract. The new media has brought unprecedented opportunities and challenges to the college students' Party building. The use of new media can realize the innovation of Party building work, and enrich the content of Party building work in order to make it have a positive effect, and also can enhance the effectiveness of Party building work. This paper makes a preliminary study on the effectiveness of college students' Party work under the new media environment.

\section{新媒体环境下大学生党建平台建设探究}

\section{李海涛}

摘要: 新媒体给是大学生党建工作带来了前所未有的机遇和挑战, 对新媒体的利用来实现党建工作的创新, 对党建工作 内容进行充实，使其产生积极作用，可以增强党建工作的实效性。本文对新媒体环境下大学生党建工作的有效进行作了初步 探讨。

关键词：新媒体、党建、实效性

在经济全球化，文化多元化，信息网络化发展的情形下，便捷，交互，开放的新媒体迅速得到广大大 学生的青睐, 并深刻影响着大学生的生活。大学生党建在新媒体环境下的挑战和机遇是我们必须予以高度 重视和认真研究思考，并提出应对方法。

\section{1 新媒体环境下大学生党建工作面临的机遇和挑战}

新媒体的发展给高校大学生党建工作带来的机遇。新媒体资源丰富、形式多样，高校党建工作者要实 行对党员的有效管理及党建活动的有效进行，可以依托新媒体进行推动。在新媒体形势下给大学生党建带 来的机遇有以下几个方面: 对新媒体的使用是开放的, 自由的, 这种有利条件使大学生党建工作更加科 学化、现代化; 新媒体资源是丰富的、形式多样的, 这可以使大学生党建工作的进行更加多样具体; 新媒 体的沟通途径是多时空的, 互动性强的, 这可以加强大学生党建工作开展的经常性和交流性。对大学生立 体党建平台的建设, 可以通过运用新媒体技术来实现, 并能通过新媒体来构建对大学生益于接受的党建工 作平台, 可以拓宽大学生党建活动的参与面, 对大学生党建活动在大学生中的接受度有明显提高。新媒体 更容易让大学生接受党建工作。因此, 对新媒体技术的充分利用可以增强高校党建活动的吸引力与凝聚力, 使学生拥有正确的人生观、价值观。

在新媒体的影响下高校大学生党建工作面临的挑战。新媒体在大学生的思维模式，行为方式，语言特 点, 心理意识中影响巨大。新媒体在大学生生活学习中的广泛应用, 使新媒体成为信息化时代的重要媒介。 
这对高校学生党建工作来说既是机遇也是一个新的挑战。而在具有广泛信息的新媒体形式下的党建工作需 党建工作者把好信息审核关, 做到对信息的有效甄别和监督, 这也是党建工作中的一大挑战。具体有以下 体现: 一是大学生思想行为方式的挑战, 新媒体平台使大学生接触到了海量的信息, 这些信息对大学生的 价值观有这很大的影响, 增加了大学生思想的复杂化。二是传统党建知识体系的挑战, 新媒体往往产生不 同于传统媒体给受众的系统性的知识，而因其信息短、更新快、便利迅捷的特点，很容易形成快餐式的阅 读现象。三是党建工作队伍建设的挑战, 新媒体的来源渠道多种多样, 但网络资源呈现出的良莠不齐的状 况给党建工作者带来了前所未有的巨大挑战。

\section{2 新媒体环境下搭建大学生党建平台的必要性和可行性}

大学生学习党建知识的主动性不足, 其原因有如下体现: 大学生对党建知识的敏感度不高, “内容枯 燥”、“形式单一”、“对个人发展没用” 在众多原因中高居前三位, 除此之外, 关于在校大学生缺乏学习党 建理论知识的主动性和积极性的原因还有 “理论感觉较难, 难以掌握”、“有无信仰并不重要” 等, 可见, 目前如何增强党建工作的吸引力和凝聚力是高校面临的主要问题。

大学生党建工作针对性和实效性不高。目前大学生党建工作仍存在很大问题, 具体体现在党建网络 平台的层次不清, 整体规划的缺乏, 发展的不平衡; 党建网站布局的重复性、随意性; 党建网络平台的更 新缓慢, 实效观念的匮乏; 网络平台内容的更新极其缓慢, 对党建网站的时效特色来说是一种弱化, 使网 络信息的吸引力降低, 价值不能体现出来; 运用网络交流的党建平台与大学生的互动交流不够。除此之外 还存在以下问题: 工作体制不健全, 对学生日常事务过于关心, 而忽略了学生的思想政治教育, 因此大学 生党建的力量不够, 缺乏对大学生党员的发展和教育的整体规划, 工作目标模糊。工作内容不全面, 党支 部工作的开展不具有针对性, 没能按照新时期大学生党建工作的发展要求进行, 因此实效性不高。工作方 式不科学, 部分高校党建工作者思想陈旧, 在工作中只注重向内灌输, 忽略受教者的主观性和自主创造能 力, 在教育形式上内容单一, 只关注内容的总体完整性, 而缺乏创新, 工作制度不完善。

新媒体已在大学生日常学习与人际交往中占据主要地位。大学生的党的理论知识的普及可以运用互 联网、移动互联网等工具来进行, 在新媒体环境下, 高校党建的现实所需是对大学生主体地位的提高, 并 通过对政策和方针的宣传和进行党史教育来增加大学生对社会热点的讨论。在对大学生对新媒体的利用上 来看, 绝大部分大学生能够熟练运用新媒体并频繁的与家人, 同学进行交流, 并且他们可以及时运用新媒 体工具来进行思想政治工作, 调查显示, 绝大多数大学生依赖于 $Q Q$ 、微信等媒体工具。此证明了新媒体工 具与党建知识的学习是可以实现相辅相成的。运用新媒体工具建设党建工作平台是可行的, 其有利点在于 可以提高大学生对党建知识学习的热情, 对党建工作来说其具有针对性和实效性。

\section{3 新媒体环境下大学生党建平台的建设目标和建设原则}

新媒体环境下高校党建平台的建设目标。大学生党建具有系统性、动态性、开放性、先进性和阶段性 等特点。对全方位、多元立体化的党建体系的构建应予以重视, 而 “全程化、全覆盖、分层递进式” 的大 学生党建工作模式是我们需要实现的。对党员和入党积极分子进行严格把关, 层层篮选, 深刻教育。设立 激励制度, 是大学生党建工作更加健全, 实现工作的可持续发展。一是对工作理念的树立需要全程化, 不 仅对学生的入党启蒙教育予以重视, 对入党积极分子的培养和考察和学生党员的发展质量也要重视, 还要 
把学生入党的后续教育列为重要位置。二是使工作网络全覆盖, 工作对象全覆盖, 在日常工作中需要将党 的基本理论、基本路线、基本纲领和基本经验贯彻到学生党员之间。三是制定分层性的工作目标。对大学 生的生活特点和成长规律做认真分析, 对不同对象的特点作出区分, 是大学生党建的重要工作, 作为育人 载体, 大学生党建需要对教育内容进行合理安排, 做到有针对性和实效性的党建教育。而对大学生党建工 作的日常制度的要求是: 保证实现规范化, 制度化, 科学化工作。党建工作的进行需要一些有良好的政治 素质、具有较高的群众威信、工作能力强、热心于党务工作的党员干部、党员教师或优秀大学生党员队伍, 从事大学生党建工作, 强化党建工作体制, 提供物质保障和资费支持, 保证党建工作的正常进行。

新媒体环境下高校党建平台的建设原则。一要以马克思主义理论为指导, 作为党建的重要组成部分, 高校党建应运用科学的理论坚定大学生党员的理想信念, 在分析和解决问题时能够自主运用马克思主义的 立场、观点和方法。大学生党建平台有着 “宣传阵地”、“與论喉舌” 的任务, 坚持马克思主义理论为指导, 是高校马克思主义大众化传播的重要途径。二要建立有大学生党建特色的党建平台, 对平台进行准确定位, 要能突出大学生党建的特色, 针对大学生党员和入党积极分子而进行的党建设计需要植根于学生党员、入 党积极分子和学生党支部, 同时面向广大学生。针对目前红色网站中仍存在大学生党员教育内容分散、教 育引导不鲜明的现象, 这就要求我们要充分利用新媒体对党建资源进行整合, 建立专业化党建平台, 建立 为大学生量身定做的党建平台, 建立具有针对性、实用性、服务性、便捷性的党建平台。三要坚持点、线、 面相结合, 立体化党建平台的建立能够使学生党支部和学生党员全方位发展, 在党建工作的开展中有效运 用新媒体技术是有创造性的, 根据点对点、点对多、多对多的原则, 建立学生党总支 $\rightarrow$ 学生支部 $\rightarrow$ 学生党 员构建体系, 做到点与面相结合。要实现如下转变, 从垂直式管理到平行性交流、从线性传播向非线性传 播、从被动教育到主动参与, 这样可以提高党组织对青年学生的吸引力和凝聚力。

\section{4 新媒体环境下大学生党建工作的主要内容及功能实现}

\section{1 主要内容}

以新媒体为传播介质, 坚持马克思主义理论, 大学生立体化党建平台, 宣传党的理论、方针、政策和 教育部的有关于党建的文件、以及从其他高校的党建工作中吸取经验; 为了加强大学生党员教育和基层学 生党支部的建设, 可以开设专家点评、党员论坛、师生对话、网络党校学堂专栏等栏目, 同时也是对科学 化, 信息化的高校党建的提升, 可以增强增强高校党建工作的针对性和实效性。

高校大学生党建工作在新媒体形势下的进一步工作是将 e 时代新媒体技术应用到高校基层党组织的 建设工作中, 这满足了高校基层党组织的工作需要, 可以增其强针对性, 操作性、实效性和感染力。对新 媒体技术充分利用, 如互联网、移动手机客户端等现代信息技术手段, 来使高校大学生党建工作具有新的 内涵和视角, 拓宽大学生党建新媒体阵地, 提升大学生党建工作的统筹力。

大学生党建平台不同于大学生思想政治教育平台的地方在于受众不同, 大学生党建平台是针对对大学 生党员和学生党支部开放的, 受众为党员、入党积极分子是一个主题教育网站, 特点是具有较强的针对性 和专业性。思想政治教育平台针对于所有大学生, 其内容很全面。大学生党建对思想政治教育来说只是一 部分。大学生立体化党建平台与传统的 “红色网站” 相比, 传统大学生党建网络传播具有功能单一, 缺少 关联性、即时性和交互性, 信息容量少, 对大数据内容无法承载的缺点。而新媒体网络传播则突破了传统 
网络传播方式的时空限制，和受众之间有广泛互动，是一个高效的综合运作模式。

\section{2 功能实现}

大学生党建综合平台的建立依托新媒体的超媒体性, 而大学生党建综合服务平台的功能开发是灵活的, 便利的, 其被开发成独立的模块, 并有高效的拓展性和机动性。要在重大思想理论问题上分清是与非, 纠 正错误的观点, 并作出有说服力的回答, 这些都可以利用新媒体的交互性来实现, 并可利用其交互性建立 交互式党建交流平台。大学生党员建设可以利用新媒体的自主性来实现, 搭建自我教育的平台, 对大学生 的素质培养和运用媒体的能力是极大的加强。

与此同时, 通过对新媒体载体的充分利用来大限度的发挥网络平台优势, 入党积极分子、学生党员的 日常培养突显 “网上党建” 育人功能, 积极利用微博、微信等信息分享传播平台, 开辟党建传播 “新阵 地”, 高校应运用相应的网络平台, 拓宽大学生党建工作的深度和广度。并组织相应活动, 宣传党建工作 的重要性, 激发大学生的工作热情, 高等院校构建大学生立体化党建平台必须与时俱进, 不断适应新技术 的发展并积极利用这些新技术。通过对新媒体工具的灵活运用实现党建宣传路径和载体的拓宽。设立在线 交流平台，广泛开展理论宣传，对时事进行深入探究，为大众提供最新的消息。

\section{参考文献:}

[1] 苪鸿岩. 新媒体技术与大学生思想政治教育 [J]。高校理论战线，2009，(6)：51-53.

[2] 邓秋萍．新媒体语境下高等学校大学生思想政治教育的探析 $[J]$ ．科技管理研究，2013，（16）：181-185.

[3] 刘立红．新媒体环境下的高等学校思想政治理论课教学研究 [J]。中国电力教育，2014，（15）：103-104.

[4] 苪鸿岩. 新媒体技术与大学生思想政治教育 [J]．高校理论战线，2009， (6)：51-53.

［5］李生，孙志爽. 新媒体背景下大学生思想政治教育工作对策研究 [J]．华章，2013，（19）：127，211.

[6] 王中坚. 新媒体环境下高校党建工作的研究与实践 [J]. 河南科技学院学报，2012，(1)：27-30.

[7] 刘晓丹．新媒体背景下高校学生党建工作面临的挑战及对策[J]。教育探究，2014，(4)：98-100.

\section{References}

[1] H.Y.Rui: New Media Technology and Ideological and Political Education of College Students[J], Theoretical Front In Higher Education, 2009,(6):51-53.(In Chinese)

[2] Q.P.Deng: The Analysis of Ideological and Political Education of College Students under the New Media Context[J], Science and Technology Management Research, 2013,(16):181-185.(In Chinese)

[3] L.H.Liu: Research on the Teaching of Ideological and Political Theory Course in Colleges and Universities under the New Media Environment[J], China Electric Power Education, 2014,(15):103-104.(In Chinese)

[4] H.Y.Rui: New Media Technology and Ideological and Political Education of College Students[J], Theoretical Front In Higher Education, 2009,(6):51-53.(In Chinese)

[5] S.Li and Z.S.Sun: Study on the Strategies of Ideological and Political Education of College Students under the Background of New Media[J], Huazhang, 2013,(19):127,211.(In Chinese)

[6] Z.J.Wang:The Research and Practice of College Party Building Work under the New Media Environment[J], Journal of Henan Institute of Science and Technology, 2012,(1):27-30.(In Chinese)

[7] X.D.Liu: Challenges and Countermeasures of College Students' Party Building Work under the Background of New Media[J], Education Research, 2014,(4):98-100.(In Chinese) 